\title{
Elevated Jewish Mortality from Coronavirus in England and Wales: An Epidemiological and Demographic Detective Story
}

\section{Daniel Staetsky ${ }^{1}$}

Received: 29 September 2020 / Accepted: 15 March 2021 / Published online: 23 April 2021

(C) The Author(s), under exclusive licence to Springer Nature B.V. 2021

\begin{abstract}
In June 2020, the Office for National Statistics (ONS) in England and Wales published the results of an investigation into mortality from COVID-19 by religious group. The analysis revealed a significant "Jewish penalty": coronavirus mortality of Jews was shown to be relatively high compared to the British Christian majority. This paper considers these findings in the light of the literature on Jewish mortality and undertakes a re-analysis of the results alongside the additional data on Jewish deaths provided by the British Jewish communal statistics. It asks two questions: (1) To what extent is elevated British Jewish mortality from COVID-19 a result of the presence of long-standing vulnerability and ill health among Jews? (2) What role do strictly Orthodox Jews play in elevating coronavirus mortality levels among British Jews? The primary contribution of the paper is to explore, via analyses of alternative data sources, the ONS finding of elevated Jewish mortality from coronavirus, to explain why it is surprising, to test whether it is real and to eliminate certain explanations. Such process of elimination in itself will highlight other alternative explanations, but the paper falls short of decisively explaining the phenomenon of the elevated British Jewish mortality from coronavirus. It ends with an outline of future directions of research in this area.
\end{abstract}

Keywords Jewish mortality · COVID-19 · Coronavirus · United Kingdom · Ethnic and religious differentials in mortality

L. Daniel Staetsky

dstaetsky@jpr.org.uk

1 Institute for Jewish Policy Research, London, UK 


\section{Introduction}

With respect to the coronavirus pandemic, the United Kingdom has been one of the worst-affected countries. The first cases of coronavirus in the UK were confirmed in January 2020, in mid-March the government advised avoiding all non-essential travel, and on 23 March 2020 a lockdown was imposed in order to prevent further transmission of the virus. These measures notwithstanding, the British level of excess mortality is estimated (from mid-March to early November 2020, cumulatively) at 110 excess deaths per 100,000 people in the population, placing the UK third in the hierarchy of the worst affected countries in Europe, after Spain and Belgium and, at the same time, somewhat above the United States (95 excess deaths per 100,000 in the population). To benchmark these levels, in Germany, Norway and Denmark the rates were in the range of 3-11 per 100,000. In Sweden, a European country that-unlike others-chose not to impose a lockdown in spring 2020, the rate was 62 per 100,000 (Economist 2020). When compared to the normal levels of mortality (an average of 2016-2019), excess mortality in England and Wales in spring 2020 was 1.4 times as high as the historical average. Large urban centressuch as London and Manchester-were especially severely affected: 1.7 times and 1.5 times, respectively. $^{1}$

In June 2020, the Office for National Statistics (ONS) in England and Wales published the results of an investigation into mortality from COVID-19 by ethnic and religious group (ONS 2020a, b, c). This was a remarkable development that came about as a result of the convergence of political will and technical aptitude. In political terms, the Cabinet Office, a department of the Government of the United Kingdom supporting the Prime Minister and the Cabinet, launched systematic data collection on ethnic and religious disparities in coronavirus mortality. The ONS, prompted by this initiative, created a new resource for mortality research by linking together the 2011 Census records for England and Wales and the national registration of deaths. Because the British Census collects data on ethnicity and religion (the national registration of deaths does not), the record linkage created a situation where tracking mortality of different ethnic and religious groups became possible. Surveys of British Jews conducted by the Institute for Jewish Policy (JPR) have indicated that about $85 \%$ of British Jews are identified as such by the national census through the question on religion.

Jews in the United Kingdom are a population of about 300,000, with England and Wales accounting for about $98 \%$ of this number-almost all of whom live in England, and over 60\% live in or around London (Graham 2013a, 2013c; Staetsky and Boyd 2015). Jews are one of the smaller non-Christian groups in England and Wales forming about $0.5 \%$ of the total population, of which $59 \%$ identify as Christian, $25 \%$ as being without religion, $5 \%$ as Muslim, $1.5 \%$ as Hindu, $0.8 \%$ as Sikh and $0.4 \%$ as Buddhist (ONS 2015). The British Jewish community is the second largest in Europe after France and the fourth largest among the Diaspora Jewish communities,

\footnotetext{
1 Author's own calculations based on: Office for National Statistics. 2016-2020. Monthly figures on deaths registered in England and Wales.
} 
after the United States of America, France and Canada (DellaPergola 2020). The socio-demographic profile of the British Jews, alongside other ethnic and religious groups, is well documented due to the existence of the census question on religion and a variety of surveys conducted by JPR. About $20 \%$ of Jews in Britain (and about $8 \%$ of adult Jews) are strictly Orthodox - the fact that makes Jews in Britain one of the Jewish communities where the process of de-secularization by demography is the most advanced (Staetsky and Boyd 2015; Staetsky and DellaPergola 2020, p. 41). About $56 \%$ of British Jewish households are affiliated to a synagogue-a proportion similar to the one observed among the Canadian Jews and considerably higher than among the American Jews (Pew Research Center 2013; Casale Mashiah and Boyd 2017; Brym et al. 2019). As a whole, British Jews are slightly older (median age of 41 in 2011) than the total British population (median age of 39), yet they are younger than the Christian population (median age of 45) (Graham 2013b). An average size of the British Jewish household (2.3 persons) is very close to the average household size in the general population (Graham and Caputo 2015). Like many Diaspora Jewish populations, British Jews are highly educated and relatively affluent: for example, 53\% of British Jews are in managerial and professional occupations, in contrast to $39 \%$ of the general population (Boyd et al. 2020).

Ethnic and religious differences in mortality in the United Kingdom are an underresearched subject, primarily due to the dearth of data resources in this area. Much of the existing body of research in this area relies on unlinked data, i.e. a situation where numerators (deaths) and denominators (population counts) of death rates originate from different sources, which raises questions concerning the possibility of numerator-denominator incompatibility (see, for example, Marmot et al. 1984; Wild and McKeigue 1997; Wild et al. 2007; Davie Smith et al. 2000; Staetsky 2011a, b; Ikram et al. 2016). Other studies rely on indirect estimation methods (Rees et al. 2009; Wohland et al. 2015). Studies that managed to procure linked data, such as the studies based on the ONS Longitudinal Study, typically focus on immigrants' mortality rather than ethnic mortality as such (Harding 2000, 2003, 2004). Important exceptions exist in this picture. Harding and Balarajan (1996), Harding (1998) and Scott and Timaeus (2013) produced studies on the basis of linked data, on the one hand, also shifting the focus to ethnic mortality rather than immigrant mortality. However, such studies are still relatively rare. Mortality differentials between religious groups in the UK have remained almost entirely unexplored to date. Thus, the ONS record linkage project is a real game changer in the study of ethnic and religious differentials in mortality.

The very first batch of results from the investigation based on the 2011 Census data set linked to the national registration of deaths showed that British Jews had elevated mortality from coronavirus. The analysis used Cox proportional hazards regression models to estimate the risk of dying from coronavirus. It revealed that with age, sex, place of residence, population density, socio-economic status and health status controlled for, the mortality of British Jews from COVID-19 was higher than the mortality of British Christians. Specifically, between 2 March and 15 May 2020, the risk of death from COVID-19 for Jewish men was almost twice as high as among Christian men, all other things being equal. For Jewish women too, elevated mortality was also observed, with their risk of death being 1.2 times as high 
as that among their Christian counterparts, all other things being equal. Muslims (men) and Hindu (both sexes) have also shown elevated mortality. Black women and men have presented elevated mortality compared to the White population (ONS 2020a, b, c).

Within the Jewish community, the ONS report seemed to confirm people's worst fears, and provide empirical evidence that Jews were significantly more susceptible to COVID-19 than others, as had been rumoured and reported since the early days of the pandemic. ${ }^{2}$ For demographers, however, the ONS report raised as many questions as it solved. At the very least, the elevated Jewish mortality result makes an unusual finding in Jewish demography. The Jewish communities of the Diaspora and Israel consistently feature in demographic studies as examples of groups with relatively low mortality, especially low "avoidable" mortality-the type of mortality that can be avoided by adjustments of lifestyle and behaviour. The evidence to this effect covers a period of over 100 years (Staetsky and Hinde 2009, 2015; Staetsky 2011a, 2011b).

Further research is required to fully clarify the reasons behind the situation, and indeed we undertook further analyses concerning the ONS findings. Our analyses rely on: (1) the rich documentation of the COVID-19 mortality investigation deposited by the ONS in the public domain; and (2) Jewish communal mortality statistics that have been collected by the Board of Deputies of British Jews historically and by JPR more recently. We consider the following questions:

1. Does elevated mortality of British Jews from COVID-19 represent a "blip", a temporary and irregular development, in an otherwise positive picture of Jewish health in Britain? Or, alternatively, although Jews in Britain have been described as a group with especially low mortality, something changed recently, and this observation is no longer true?

2. What role do strictly Orthodox Jews play in elevating coronavirus mortality levels among British Jews?

The following sections examine the available evidence necessary to answer these questions. It should be stated explicitly that the paper falls short of fully explaining Jewish mortality from COVID-19. This is impossible at present and will only become possible when mortality from coronavirus in general is better understood, both at an individual and an aggregate level. The primary contribution of the paper is to explore, via analyses of alternative data sources, the main ONS finding of elevated Jewish mortality from coronavirus, to explain why it is surprising, to test whether it is real and to eliminate certain explanations. The concluding section returns to the topic of possible explanations and contains a brief discussion

\footnotetext{
${ }^{2}$ For just two examples, see: Frot, M. 2020, March 25. 22 UK Jews have died after contracting coronavirus, figures show, Jewish News, https://jewishnews.timesofisrael.com/at-least-20-uk-jews-have-diedafter-contracting-coronavirus-figures-show/. Heilman, U. 2020, May 5. How the coronavirus hitting the Jewish communities worldwide, a country-by-country breakdown, Jewish Telegraphic Agency, https:// www.jta.org/2020/05/05/global/how-the-coronavirus-is-hitting-jewish-communities-worldwide
} 
of the next steps needed to make progress in understanding Jewish mortality from coronavirus.

\section{How to Understand the ONS Finding of Relatively High Jewish Mortality from COVID-19 in England and Wales}

The ONS report on COVID-19 mortality highlighted heightened levels of Jewish mortality. Seen in the perspective of existing research on Jewish mortality in Israel and the Diaspora, that finding was very unexpected, almost incredible. Jews are "long-lifers", one of the social groups with the lowest mortality possible in contemporary society. So the finding demands that we ask what happened to normally low Jewish mortality? Is it still here? If so, how can we explain the ONS finding of heightened mortality in the COVID-19 pandemic? Or, might it indicate that the tables turned in the early twenty-first century and Jews became-all of a sudden-a group with high mortality, perhaps due to the accumulation of more elderly and frail individuals as a result of very low mortality prevailing in the past, as some commentators have suggested? Alternatively, could it be that the explicit diagnosis of COVID-19 is present in a greater proportion of Jewish death certificates compared to others simply because Jews tend to seek medical attention and investigations more readily than others-another hypothesis that has been suggested?

These questions are not strictly of analytical interest. The answers matter for policy in the context of the COVID-19 pandemic. If Jewish mortality today is generally high, then heightened COVID-19 mortality may be simply an expression, or an aspect, of this general state of affairs. What then needs to be explained and tackled by policy, if possible, is the issue of high mortality in general rather than in the specific case of COVID-19 mortality. This is precisely how the finding of elevated COVID-19 mortality in the Black, Asian and minority ethnic (BAME) population is interpreted, rightly or wrongly. In that case, the finding of high mortality is perhaps not unexpected, because previous research on health and mortality inequalities has long pointed out the compromised state of health among these subgroups within the British population. If, on the other hand, Jewish mortality is still generally low, as a rule, and COVID-19 mortality is unusual, what needs to be understood in the particular case of the COVID-19 pandemic is what gave rise to that particular, and uncharacteristic, outcome. Might it be something to do with the behavioural characteristics of Jews, i.e. the nature of their social and religious lives or perhaps non-compliance with government directives? Thus, the policy responses to these two situations could be dramatically different, and the stakes are high. So, in short, is Jewish mortality still low in general, but abnormally high during the COVID-19 pandemic, or is it now high in general, and therefore "appropriately" high also at the time of pandemic?

\section{Could it be an Artefact?}

Do Jews have a higher tendency to seek medical investigations and diagnosis compared to others? This could be the case and not due to any cultural peculiarities but 
for the simple reason that Jews are over-represented among the members of the top socio-economic groups in Britain, and these groups tend to seek medical attention more readily than others. If so, this could have led to the wrong impression that Jewish mortality from COVID-19 is relatively high, while in reality it is just a result of better diagnosis and subsequent appearance of the correct cause of death (in this case COVID-19) on death certificates. In order to test this hypothesis, we turned to the Jewish communal statistics of deaths and conducted an estimation of excess mortality, i.e. the extent to which mortality from all causes among Jews was elevated during the time of the pandemic. We then estimated the proportion of deaths classified as being due to COVID-19 out of the total number of excess deaths among Jews. Finally, we repeated this exercise with respect to the total population of England and Wales which made it possible to compare Jews to the total population.

A few words of clarification of the method for estimating excess mortality are in order. Early in the course of the coronavirus pandemic, the community of epidemiologists realized that trying to count COVID-19-related deaths directly, on the basis of the presence of COVID-19 as such on death certificates, is an approach ridden with uncertainties. This was for reasons independent of the (suspected) differential propensities of different social groups to seek medical investigations. First, COVID19 is a novel disease, and it is not well established in practice of the medical community. Second, it is an illness that forms synergies with pre-existing conditions, and for this reason alone it may be subject to misreporting and under-reporting. Like influenza, a well-understood illness, COVID-19 possesses inherent ambiguity due to the synergies it forms. Estimation of excess mortality is based on quantification of the deviation of total mortality (i.e. mortality from all causes) during the time of the epidemic from the expected schedule of mortality, which is a schedule observed pre-pandemic. Due to its technical simplicity and independence from the COVID-19 diagnosis, the method of estimation of excess mortality became widely practiced (OECD 2020; The Economist 2020; The Financial Times 2020), and we followed this trend.

For many years, the Board of Deputies of British Jews and-more recently-JPR have collected data on the number of deaths in the UK Jewish population. Jewish burial societies bury Jews who hold membership of a synagogue and also the Jewish non-members, and they do not hold non-Jewish deaths. This exclusive mode of operation made burial societies an invaluable source of statistics on Jewish deaths under the conditions not allowing identification of Jewish deaths from death certificates. The numbers of Jewish deaths over the years matched the size of the Jewish population. The results of the ONS analysis clarified that the proportion of Jewish deaths handled by the burial societies out of the total number of Jewish deaths in the UK is close to $85 \%$. Further in this paper we present an assessment concerning the degree of compatibility between the Jewish deaths handled by the burial societies and the Jewish population enumerated in the census.

In spring-summer 2020 we contacted Jewish burial societies across England and Wales (but excluding Scotland at that point) for the up-to-date counts of Jewish deaths by month and for the historical data in the same format. The existence of these data makes it possible to reconstruct the "normal" level of Jewish mortality: the "normal", or expected, level would be indicated by the average number 

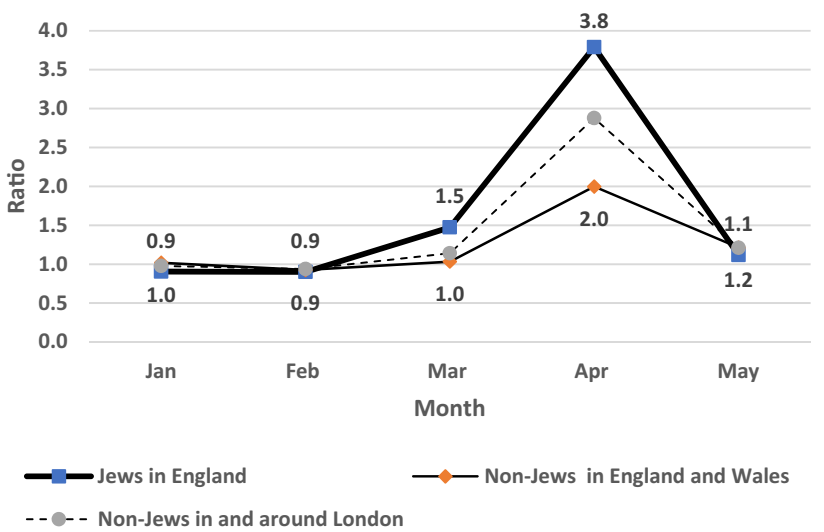

Fig. 1 The ratios of the number of deaths in 2020 to the average number of deaths in 2016-2019 among Jews and non-Jews, by month, in England. Note: By the end of June 2020 we managed to collect the data from burial societies responsible for handling about $50 \%$ of all Jewish deaths in the United Kingdom. See the next section for the exposition of compatibility between the records held by the Jewish burial societies and the national registration. Source: author's calculations based on: (1) Jewish deaths communicated by the Jewish burial societies in England, and (2) non-Jewish deaths: Office for National Statistics. 2020. Monthly provisional figures on deaths registered in England and Wales. https://www.ons.gov.uk/ peoplepopulationandcommunity/birthsdeathsandmarriages/deaths/datasets/monthlyfiguresondeathsreg isteredbyareaofusualresidence

of deaths occurring during the years preceding the pandemic (e.g. 2016-2019). It is also possible to estimate the excess deaths as the seasonal "surplus"- the difference between the total number of deaths observed during the pandemic and the expected number. Our assessment is that 642 excess Jewish deaths took place in England and Wales in the period of 2 March-15 May 2020. The ONS analysis identified 453 Jewish deaths from COVID-19 (503, allowing for $10 \%$ of unlinked deaths, see ONS 2020a, b, c for details). Thus, $78 \%$ of all excess Jewish deaths had a "COVID-19" diagnosis stated explicitly on death certificates (as 503/642*100). In the general population, the respective figure was similar. In total, 166,577 deaths were registered in England and Wales in 2 March-15 May 2020, which was 52,709 deaths higher than the average figure for this period in 2016-2019 (excess deaths). In this period, 41,105 COVID-19 deaths were registered across England and Wales, ${ }^{3}$ thus the proportion of COVID-19 deaths out of all excess deaths is calculated as $41,105 / 52,709 * 100=78 \%$. Thus, relatively high Jewish mortality from coronavirus in Britain is not an artefact; it is a reality.

Armed with this insight, we can better understand the finding of excess mortality among Jews. Figure 1 sets out the ratios of the number of deaths from all causes that occurred among Jews in the months of January-May 2020 to the numbers observed

\footnotetext{
${ }^{3}$ The source of information on registered deaths in England and Wales in 2 March-15 May 2020 is: ONS, Weekly provisional figures on deaths registered where coronavirus (COVID-19) was mentioned on the death certificate in England and Wales, deaths up to week ending 19 June 2020, https://www.ons. gov.uk/peoplepopulationandcommunity/birthsdeathsandmarriages/deaths/bulletins/deathsregisteredweek lyinenglandandwalesprovisional/weekending 18 september2020.
} 
in the pre-pandemic years. Jews in England indeed have higher mortality during the time of the pandemic. At its peak, in April 2020, Jewish mortality was almost twice as high as mortality among non-Jews, and it was 1.3 times as high as mortality among non-Jews with place of residence controlled for. A majority of Jews in England live in and around London, a place with especially high coronavirus mortality. For this reason, the most appropriate comparator of non-Jewish excess mortality from coronavirus relates to the areas of London.

The "Jewish penalty" with respect to coronavirus mortality in England, found by the ONS, is at a level of 1.8 when expressed as a hazard ratio, controlling for age. Thus, the excess mortality estimation and the ONS analysis agree concerning the scale of the "Jewish penalty". The comparison confirms that the difference in age structure of Jews and non-Jews has a modest effect on the "Jewish penalty": the penalty is observed with age being controlled for (the ONS analysis) and without (the excess mortality estimation). The "Jewish penalty" is not a compositional artefact either.

\section{A Long-Standing Vulnerability? A Further Insight from Jewish Communal Statistics of Deaths}

Should the levels of excess mortality among Jews during the pandemic be understood as an expression of long-standing Jewish vulnerability and ill health, or are they due to some irregular, transient factors? As previously mentioned, Jewish mortality across time and space has been repeatedly found to be lower in comparison to mortality of non-Jews. Staetsky's findings (2011b) suggested that this may be also true of the British context around the turn of the century, yet his findings were based on unlinked data, and in any case, the situation could have changed in the meantime. In this section, we clarify the contemporary situation with Jewish mortality outside of the coronavirus pandemic times utilising the Jewish communal statistics. However, before this can be done, the fundamental issue of compatibility of Jewish communal statistics on deaths with the census and national registration of deaths in the Jewish population must be settled.

The compatibility of deaths and the census counts follows from the following considerations:

1. The ONS record linkage exercise identified 1029 Jewish deaths from all causes in the period of 2 March-15 May 2020. What makes these deaths "Jewish" is the fact the people who died appeared as Jews in the 2011 Census of England and Wales. The ONS was highly successful in the linkage of the Census records to the death registrations: about $90 \%$ of deaths occurring in the period above were successfully linked to the 2011 Census. Adjusting for the unlinked Jewish deaths renders the true number of Jewish deaths in this period as 1143 (calculated as $1029 * 100 / 90)$. Admittedly, the ONS counts relate to the Jewish population in the 2011 Census. This population would have changed somewhat in the intervening decade. The actual Jewish population in 2020 includes all children born since the 2011 Census and excludes all deaths since the 2011 Census. It also contains the net changes as a result of migration. The changes are inconsequential with respect 
to the number of deaths expected to take place in 2020. Mortality among children has a very low impact on the total number of deaths. The size and structure of the elderly population, responsible for nearly all mortality, could not have changed significantly since 2011.

2. Alongside the ONS project, JPR launched its own data collection exercise, as briefly mentioned in the previous section. It contacted the major Jewish burial societies in England asking for the counts of deaths by month. The specific burial societies included in this analysis are: United Synagogue, West London Synagogue, Spanish and Portuguese Sephardi Community Burial Society, Western Charitable Foundation and North Manchester Jewish Cemeteries Trust. These societies communicated their data by mid-June 2020, when the data collection for this project had finished. The counts of deaths included traditional Jewish burials and cremations. Examination of historical records had shown that the burial societies mentioned above handled about $50 \%$ of all Jewish deaths in the UK in years 2016-2019. In sum, for the period of 2 March-15 May 2020 (exact equivalent to the period covered by the ONS analysis), 568 deaths were counted across the burial societies in question. When adjusted for the partial coverage (50\%), the number of deaths registered in the Jewish community in 2 March-15 May 2020 appears to be 1136 , which is very close to the number of deaths identified by the ONS.

3. The ONS record linkage exercise covered England and Wales and excluded Scotland where about $2 \%$ of all Jews in the UK resided in 2011. Accounting for presence of Scottish Jews (e.g. if the record linkage exercise covered Scotland, with the same quality of linkage) would have brought the total number of Jewish deaths in the UK to $1166(1143 * 100 / 98)$. The conclusion regarding the compatibility is not sensitive to this adjustment.

Evidently, close alignment of the Census-based and the communal counts of deaths is a very significant finding. It is presented here for the first time in the history of this subject. Previous research into the Jewish mortality in the United Kingdom openly admitted the possibility of the numerator-denominator incompatibility in the unlinked data underlying the calculation of the Jewish death rates and went to considerable lengths to test the sensitivity of conclusions regarding Jewish mortality to this possibility (Staetsky 2011b). Yet, the possibility to actually ascertain the compatibility in strict empirical terms has not presented itself until now. Such ascertainment has multiple ramifications in that it significantly increases our understanding of the demographic behaviour of the British Jews. Assessment of its full consequences has no place in this paper dedicated to the topic of mortality, but it will form the focus of future papers. In the meantime, the interested reader can consult Appendix 1 of this paper that contains information on the compatibility of the census and the Jewish communal statistics on births.

The scene is now set for the assessment of the contemporary situation with Jewish mortality outside of the coronavirus pandemic times. Drawing on Jewish communal statistics, in 2011-2016 (years of normal mortality), the average number of deaths in the UK Jewish community was in the range of 2400-2540 (Casale Mashiah 2018). Is this level high or low? A number of deaths as such is not a window into the level 


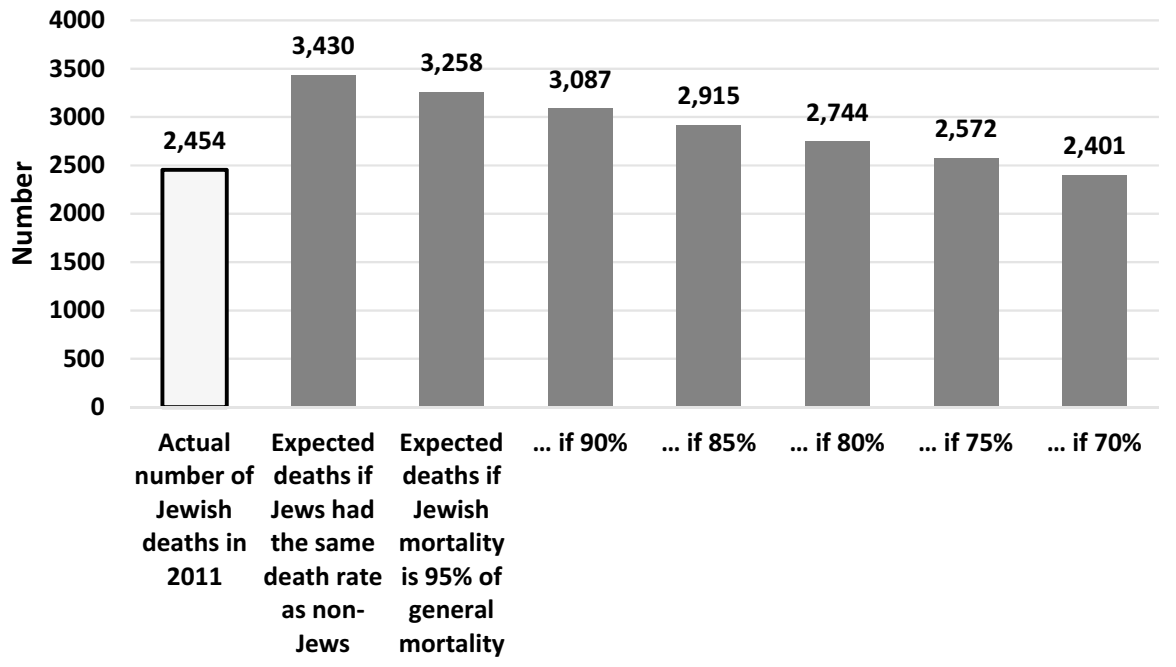

Scenario

Fig. 2 Actual and expected Jewish deaths in Britain under different assumed levels of mortality, 2011. Source: author's calculations based on (1) Casale Mashiah, D. 2018. Vital statistics of the UK Jewish population: births and deaths. JPR Report, June 2018; (2) Office for National Statistics. Deaths: age, sex and marital status, 2010, 2011, 2012; (3) Office for National Statistics. 2011 Census Table DC2107, available at NOMIS, official labour market statistics, https://www.nomisweb.co.uk/; and (4) Scotland's Census. 2011 Census Table SC2107, available at https://www.scotlandscensus.gov.uk/ods-web/home. html

of mortality. It is shaped, over and above the force of mortality itself, by other factors, such as the size of a population and its age composition. A large population would have a larger number of deaths than a small population, even if its mortality (i.e. the underlying risk of death) is lower. This point is obvious, almost intuitive. And a very aged population (i.e. a population containing a large proportion of the elderly) would have a higher number of deaths compared to a relatively young population of an equal size and with the same level of mortality. Thus, to have a clear view of Jewish mortality, one ought to control for Jewish population size and age structure. The exercise reported below controls for both factors.

To clarify the level of Jewish mortality (i.e. the mortality rate, the measure of vulnerability), we can apply mortality rates for the general population of England and Wales to the age and sex distributions of the British Jewish population found in the 2011 Census and compare the number of deaths that such an exercise renders to the actual number of deaths (2450 in 2011). If Jewish mortality (namely, the mortality rate) is the same or very close to the rate of the general population, the projected number of deaths would indeed be in the region of 2450. If, on the other hand, Jewish mortality in reality is lower than the mortality of the general population, then the application of the general rate to the Jewish age and sex structure would produce a higher number than 2450 .

The results of this exercise are set out in Fig. 2. The number of Jewish deaths we would expect to see in a given year, assuming that general mortality and Jewish 
mortality are equal, is 3430 , which is about $40 \%$ higher than 2450 . We can conclude that, under normal circumstances, Jewish mortality is indeed lower than general mortality. It follows then that the ONS finding of elevated COVID-19 mortality among Jews is an aberration, an exception to the rule.

Further, Fig. 2 also shows an attempt to figure out, by the method of sensitivity analysis, the approximate level of British Jewish mortality. In this exercise, we gradually reduced the level of general mortality (by 5\%, 10\%, 15\%, 20\%, 25\% and $30 \%$ ) and recalculated the number of deaths we would expect to see in the British Jewish population under the new schedule. The number of deaths approximating the actual level can only be achieved at a level of mortality that is $70-75 \%$ of (or 25-30\% lower than) general mortality. Experimentally, using the same method, we established that British Jewish mortality is lower than mortality of Jews in Israel: death rates of Jews in Israel around 2011 were applied to the British Jewish age and sex structure; this exercise produced 3135 deaths. This is not a definitive statement of how low British Jewish mortality actually is, but a rather unambiguous indication that-outside of COVID-19 times-it is substantially lower than general mortality in Britain. Had this not been the case, we would have seen, under normal circumstances, a much higher number of deaths among Jews.

These conclusions are aligned well with the previous work on the subject of British Jewish mortality where similar observations were made. In particular, superior longevity of British Jews was interpreted as a joint outcome of their superior socioeconomic situation and the adherence to a more health-protective lifestyle, compared to the general population in Britain. Superior socio-economic situation also shaped the longevity advantage of British Jews compared to Israeli Jews, but different migration histories of the two populations also played their role. Among Israeli Jews, a significant part of the older adult population still consists of migrants from parts of the world characterised by relatively high mortality, e.g. Eastern Europe, the Middle East and North Africa, which inflates its mortality somewhat (Staetsky 2011b).

\section{A Closer Look at the ONS Findings}

Closer examination of the ONS findings, based on the detailed documentation of their new data product, provides further support to the claim that high COVID-19 mortality among Jews is an aberration. The ONS documentation tells us that, among those aged 65 years and over, there were 430 certified COVID-19 deaths in the Jewish population during the period 2 March-15 May 2020. ${ }^{4}$ The total number of Jewish deaths in this age group in that period was 980 . We can remove the COVID19 deaths from the total number of Jewish deaths to re-estimate mortality rates in March-May 2020. ${ }^{5}$ The result of this exercise for Jews and an identical exercise

\footnotetext{
4 The ONS counts of Jewish deaths mentioned in this section relate to the population of Jews appearing in the 2011 Census file.

5 In order to do so, we derived the denominators of the death rates around 2020 on the basis of the sizes of the religious groups in the 2011 Census (Census Table DC2107EW). Specifically, we applied Israeli Jewish death rates in 2017 to the 2011 Census counts of Jews in England and Wales. This made
} 


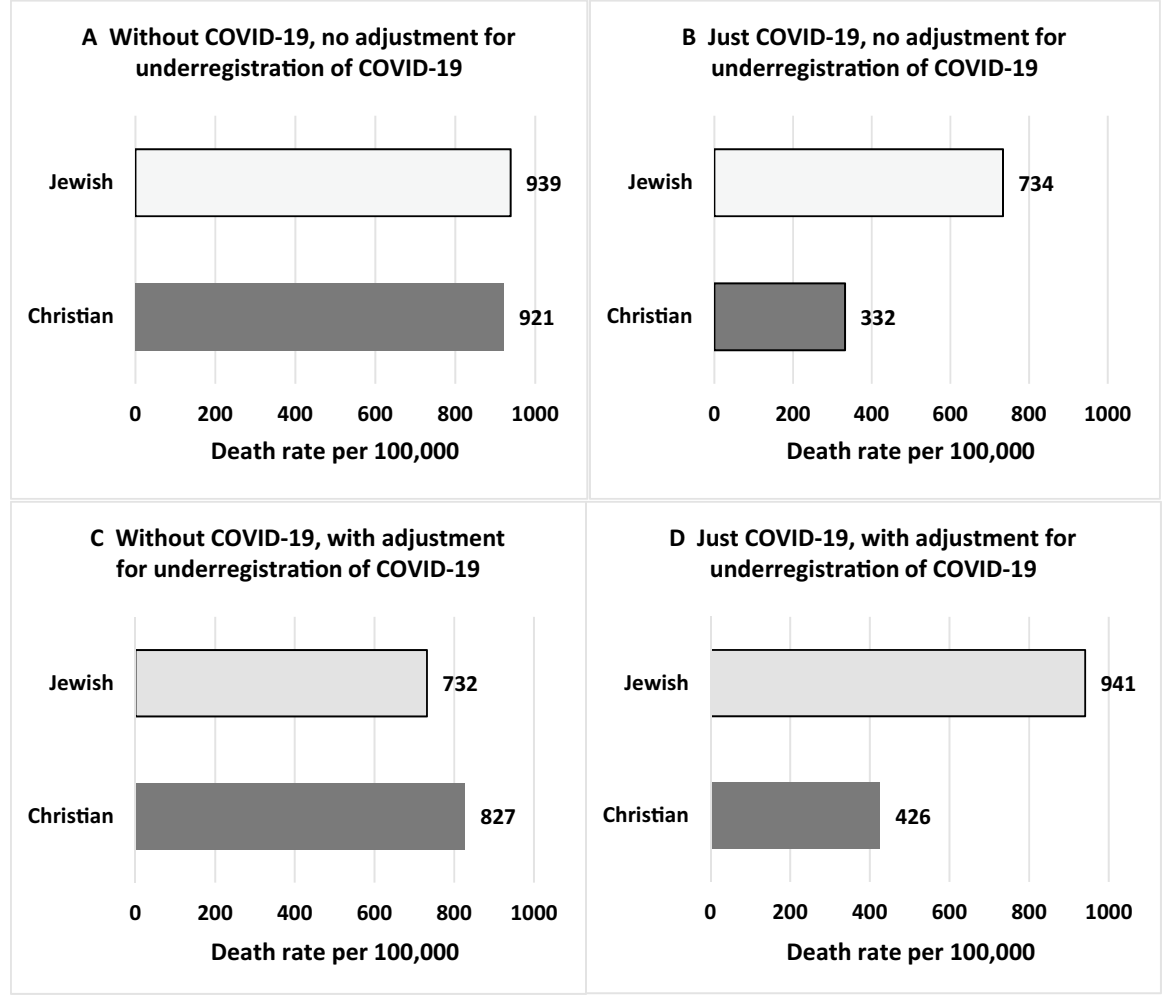

Fig. 3 Simulated death rates for religious groups just for COVID-19 and without COVID-19 in MarchMay 2020, age 65 years and over. Note: the rates are for age groups 65 years and over, but are not standardised to reflect the internal age composition of this group. The proportion of British Jews aged 85 and over out of those aged 65 years and over is higher than the respective proportion among Christians. Source: author's calculations based on: (1) supplements to the ONS report: ONS. 2020. Coronavirus (COVID-19) related deaths by religious group, England and Wales, 2 March-15 May 2020; and (2) 2011 Census Table DC2107, available at NOMIS, official labour market statistics, https://www.nomisweb.co.uk/

for Christians is illustrated in Fig. 3. The comparison to Christians is made for the analysis to resemble the comparison originally made by the ONS. Panels A and B

Footnote 5 (continued)

it possible to reconstruct the Jewish population in England and Wales around 2020. Given that Israeli Jewish death rates are likely to be somewhat lower than the death rates of British Jews, such an application results in underestimation of the Jewish population counts around 2020. This, in turn, results in a certain degree of overestimation of British Jewish death rates in 2020. We also took into account Jewish migration from the United Kingdom to Israel between 2011 and 2020. Further, we derived the denominators for Christians, applying deaths rates in England and Wales (2012-2018) to the Census counts of Christians in 2011. We could not account for migration among Christians. We do not expect this to affect the estimation dramatically, though it is worth remembering that Christians' death rates are likely to be somewhat underestimated as a result. The comparison of the possibly overestimated British Jewish death rates with the possibly underestimated British Christian death rates makes the discovery of any survival advantage among British Jews inherently difficult. Data on death rates of Israeli Jews and migration to Israel are from the Central Bureau of Statistics-Israel; data on death rates of Israeli Jews in England and Wales are from the Human Mortality Database (https://mortality.org/). 


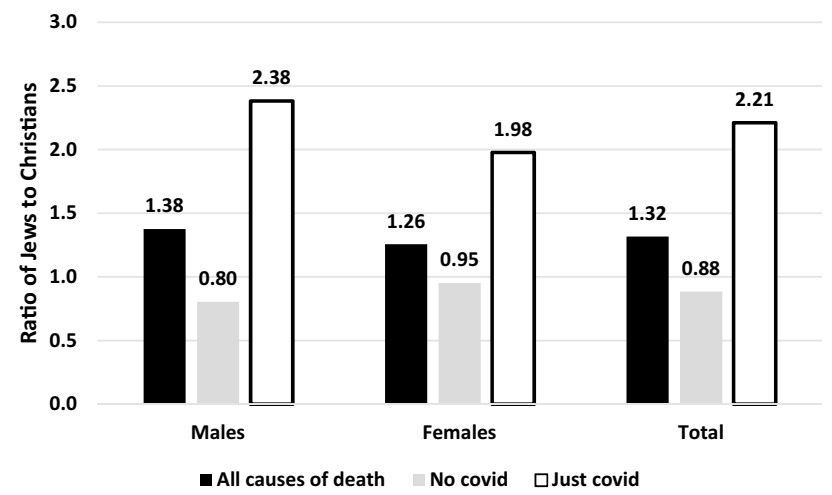

Fig. 4 Ratios of Jewish to Christian deaths rates in March-May 2020, with and without COVID-19, age 65 years and over. Note: See note for Fig. 3. Source: author's calculations based on (1) supplements to the ONS report: ONS. 2020. Coronavirus (COVID-19) related deaths by religious group, England and Wales, 2 March-15 May 2020, and (2) 2011 Census Table DC2107, available at NOMIS, official labour market statistics, https://www.nomisweb.co.uk/

show the results of the simple re-estimation of mortality rate, while Panels C and D present a re-estimation that also takes into account a certain degree of under-registration of COVID-19 deaths in the national statistics. ${ }^{6}$

In terms of mortality, the change in the position of Jews relative to Christians as a result of the exclusion of COVID-19 deaths is radical. Without COVID-19, the Jewish death rate in March-May 2020 is either about the same as the Christian rate (panel A) or lower than among Christians (panel C). On the other hand, the specifically COVID-19 death rate is much higher. For reasons having to do with data availability, the death rates for Christians are almost certainly underestimated, while the rates for Jews are overestimated, and the Jewish advantage in non-COVID-19 mortality does not appear to be as decisive as it is in reality. ${ }^{7}$

Finally, for a more concise exposition, Fig. 4 shows the ratios of Jewish to Christian death rates in March-May 2020 - for all causes of death; for COVID-19 deaths only; and for non-COVID-19 deaths. A ratio of 1 indicates equality of the Jewish and Christian death rates, a ratio above 1 indicates Jewish disadvantage (higher Jewish mortality), while a ratio below 1 signals Jewish advantage (lower Jewish mortality). The exhibit summarises the finding: the Jewish mortality disadvantage in March-May 2020 is driven exclusively by COVID-19. With reference to males, without COVID-19, Jewish mortality is relatively low (a ratio of 0.88), yet with COVID19 included it is relatively high (a ratio of 1.32). Such transformation following the inclusion of COVID-19 is understandable in view of the fact the Jewish mortality

\footnotetext{
${ }^{6}$ See section "Could it be an artefact?" on the scope of under-registration of COVID-19.

7 Firstly, the denominators of Christians' death rates may include people who moved abroad between the date of the 2011 Census and early 2020. Inflated denominators translate into suppressed death rates. Secondly, even though the death rates are calculated for ages 65 years and over, within this group, British Christians are somewhat younger than British Jews. This too remains unaccounted for in the calculation of the rates presented here and gives a further mortality advantage to British Christians.
} 


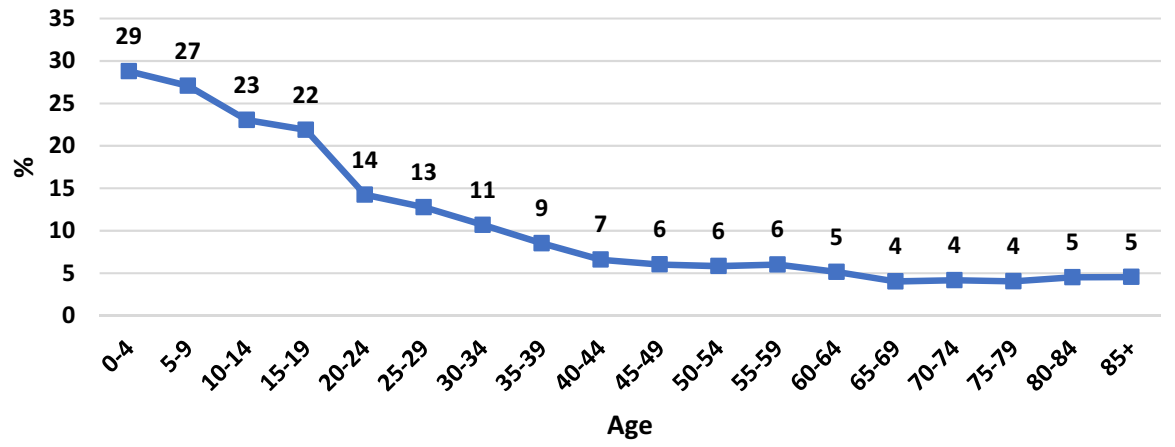

Fig. 5 Percentage of strictly Orthodox Jews in the total Jewish population in England and Wales, 2011 Census. Note. The definition of "haredi" includes all Jews enumerated in the London boroughs of Barnet (wards of Golders Green and Hendon only), Hackney (wards of Brownswood, Cazenove, Lordship, New River and Springfield only) and Haringey (ward of Seven Sisters), as well as three local authorities outside of London: Bury (ward of Sedgely) and Salford (wards of Broughton and Kersal), both of which are in Greater Manchester, and Gateshead. In 2011, these locations combined included the vast majority of the British haredi population. Source: author's calculations on the basis of the 2011 Census data for England and Wales

from COVID-19 is over twice as high as the mortality among Christians. In essence, COVID-19 managed to affect the Jewish population in a way all other causes of death have not; it suppresses the underlying low mortality, making Jews appear to be as disadvantaged as Black, Asian and minority ethnic populations, even though they are not.

\section{The Haredi Factor?}

The haredi-or strictly Orthodox-Jewish population is a large minority among Jews in Britain, about 20\% (Staetsky and Boyd 2015; Staetsky and DellaPergola 2020, p. 41). Residential patterns of the haredi in Britain are well documented: they tend to live in rather homogeneous clusters across London, Manchester and Gateshead. A significant degree of spatial separation between the haredi and non-haredi Jews facilitated the construction of the reliable estimates of the haredi population on the basis of the census datafile.

The haredi population has a very small input into the picture of mortality of British Jews. This is true both in normal times and at the time of the pandemic. In Israel, the only context so far where direct estimation of strictly Orthodox Jewish mortality has been possible, haredi mortality was found to be no different from the mortality of other Jews. In 2013-2017, in Israeli localities where haredi Jews are numerically dominant (Modiin Illit, Bnei Brak and Beitar Illit), life expectancy was in the range of 82.7-87.6 years, whereas for Israel as a whole it was 82.6 years (Central Bureau of Statistics, Israel 2019).

Haredi mortality from COVID-19 is not something that is possible to estimate at present, in England, Israel or elsewhere. On the other hand, it is clear that the numerical weight of the strictly Orthodox Jewish population in the age groups 
influencing mortality (and the ONS findings) is very low. Figure 5 plots the estimated proportions of haredim in the Jewish population of England and Wales, by age, in 2011. At ages 55 years and over (which are ages 65 years and over around 2020), only 5\% of all Jews in England and Wales are haredi. Due to high fertility among the haredi, their proportion among children is much higher, signalling an unfolding compositional change in the British Jewish population (Staetsky and Boyd 2015). However, in terms of mortality, the haredi simply cannot be influential and could not have impacted on the ONS conclusions regarding elevated Jewish mortality from COVID-19, for two key reasons. First, 95\% of the Jews covered by the ONS analysis belong to the mainstream Jewish population, so they are the group most likely to be shaping and dominating the ONS findings. Second, to confirm this, data on Jewish burials collected by JPR directly from Jewish burial societies demonstrate that the phenomenon of elevated mortality from COVID-19 exists across the entire spectrum of Jewish religious observance in England, and is not limited to the most religiously observant pockets. Deaths in March-May 2020 in the mainstream Orthodox Jewish community were 2.2 times the expected level, compared to 1.7 times among non-Jews in London and Hertfordshire, for example.

Our assertions above should not be construed as a suggestion that this community had not been impacted by COVID-19 or, alternatively, that it had been impacted in a manner similar to, or different from, the rest of the Jewish community. In fact, prevalence of infection was shown to be very high among the British haredi: overall seroprevalence of $64 \%$, in contrast to $7 \%$ nationally and $11 \%$ in London (Gaskell et al. 2021). Simply, the very modest presence of the haredi in age groups relevant to the analysis of mortality means that the overall profile of COVID-19 mortality of Jews in Britain is shaped by the non-haredi. At present, we have no insight into haredi mortality from COVID-19. Assessment of the haredi mortality is something for future research to address.

\section{Summary and Conclusion}

Initially, the ONS findings on British Jewish mortality from COVID-19 looked incomprehensible in light of the existing research on Jewish mortality globally and in the UK. Unknowingly, from the point of view of Jewish demography, the ONS wrote a "detective story". The ONS investigation revealed the existence of "Jewish penalty", i.e. that Jewish mortality from COVID-19 was high relative to the country's majority population, even after multiple controls for age, household composition, state of health, socio-economic status, region of residence and some other characteristics that shape mortality outcomes. Yet, evidence has long demonstrated that Jews are "long-lifers"; compared to many other populations, they have low mortality. Hence, the initial doubts and scrutiny of the results.

Our investigation has shown that these results are correct and do not contradict the whole historical-demographic body of literature. They show, simultaneously, that Jewish mortality due to COVID-19 is high, but it remains low outside of this pandemic period and event. Thus, in brief, the ONS finding of the Jewish mortality disadvantage during the pandemic is real, but it is also unique, and emphatically not 
an expression of long-standing vulnerability and ill health of British Jews, which may be the case with some other population groups highlighted by the ONS analysis for their elevated mortality (e.g. BAME). To put it differently, the "Jewish penalty" in coronavirus mortality in the UK is a case of elevated mortality in an otherwise low-mortality population. Further, our analysis has shown that the high mortality levels from COVID-19 found among Jews is not caused in any significant way by any particular developments occurring in the strictly Orthodox (haredi) population. This population is simply not numerous enough in the age groups that suffer the most from COVID-19 pandemic. Additionally, other, less religious subgroups of Jews were severely affected by COVID-19, more so than the non-Jewish population surrounding them.

These findings are worth placing in the context of wider debates around the determinants of COVID-19 mortality. Early in the course of the pandemic, age was highlighted as a key determinant of mortality at an individual and an aggregate level (Balbo et al. 2020a; Dowd et al. 2020a). Later, the impact of age on COVID-19 mortality was confirmed by Lee and Goldstein (2020) who showed that age-specific mortality risks for COVID-19 are similar to the risks exhibited by the all-cause mortality. Like all-cause and influenza mortality, COVID-19 mortality increases exponentially with age. The early speculations about the fate of Jewish communities under the "COVID-19 regime" focused on the difference in age structure between Jews and non-Jews as a meaningful factor capable of creating a "Jewish penalty." The ONS analysis has clarified that the "Jewish penalty" in Britain exists independently of age structure. Indeed, British Jews-of whom $21 \%$ are aged 65 years and over-are older than the total population of England and Wales (16\% are aged 65 years and over), yet this relatively small difference is obviously not something that can create the Jewish penalty. ${ }^{8}$ Moreover, recently published research concerning international comparisons of COVID-19 mortality indicates that, controlling for the timing of the pandemic, age differences between populations do not explain the existing differences in volume of coronavirus mortality. Countries with the highest levels of COVID-19 mortality (e.g. the United States) are not the countries with the oldest age structure, and countries with rather old age structures (e.g. Germany) have a low volume of coronavirus mortality (Bilinski and Emanuel 2020). The same is true of Jewish communities, with some of the oldest Jewish communities (Germany and Hungary) being considerably less affected compared to some younger communities, such as Britain (Staetsky and Paltiel 2020).

Intergenerational contact and living arrangements were also highlighted as potentially important factors behind mortality from COVID-19 (Balbo et al 2020b; Dowd et al. 2020a, b; Esteve et al. 2020). Increased social contact, for example, co-residence of the elderly with their grown children as well as involvement of the elderly in childcare support, was hypothetically linked to increased exposure to COVID-19. Subsequently, research demonstrated that, for older individuals, residing with working-age individuals was associated with increased COVID-19 mortality (Branden

\footnotetext{
${ }^{8}$ Office for National Statistics. Table DC2107EW-Religion by sex by age. Nomis Official Labour Market Statistics. Data set Selection-Query-Nomis_Official Labour Market Statistics (nomisweb.co.uk).
} 
et al. 2020). Yet, this conclusion, obtained at an individual level, did not receive unambiguous support at an aggregate level (Arpino et al. 2020; Aparicio and Grossbard 2020; Dowd et al. 2020b). In any case, the "Jewish penalty" in Britain holds good with the effect of household composition controlled for as the ONS analysis showed. In this situation, there are three remaining avenues for investigation: (1) Jewish genetics; (2) the role of the care homes for the elderly and (3) prevalence of infection in the Jewish population.

Genetic factors have been speculatively suggested as a potential explanation behind the "Jewish penalty". Yet, recent comparative analysis of Jewish mortality from COVID-19 documented the existence of wide differences between Jewish communities across the globe in the degree of impact of coronavirus mortality. Significant excess mortality during the coronavirus pandemic was observed, for example, in the whole of Britain, Brussels (Belgium), Milan (Italy), Stockholm (Sweden) and New York (the USA), but in Paris (France), Amsterdam (the Netherlands), Antwerp (Belgium), Rome (Italy), Budapest (Hungary), Toronto and Montreal (Canada) and many places in Germany, the excess was much smaller. The extent of "Jewish penalty" varied too (Staetsky and Paltiel 2020). The impact of the genetic factors cannot be dismissed on the basis of wide variation, though in itself, the existence of wide variation in mortality suggests that non-genetic factors may dominate the picture.

The role of the care homes for the elderly fares no better. Across Western countries, the proportion of all COVID-19 deaths that were care home residents is $47 \%$ (Comas-Herrera et al. 2020). Theoretically, given the significance of mortality in care homes, the difference in the scope of residential care between countries could in itself explain at least part of the differences in COVID-19 mortality. Yet, in the specific case of British Jews, this factor cannot be influential. Based on the 2011 Census, the approximate share of the population aged 65 years and over in England and Wales is 3.8\% and it is about 5.4\% among Jews (ONS, Census Tables DC4409EWla and DC2107EW). A difference on this scale is not expected to have a perceptible impact on differences in mortality.

Where next? It is this author's view that future research should now be specifically about why COVID-19 affected Jews in the UK particularly badly notwithstanding their generally low mortality. The leading hypotheses now are that the sheer presence (prevalence) of COVID-19 infection was either: (1) higher initially in British Jews or (2) was the same/smaller in British Jews than others, but spread more quickly among Jews. Both alternatives require exploration. With respect to the first possibility, Jews as a community could be among those who picked the virus earlier due to significant scope of international travel. The eruption of the coronavirus pandemic in Britain was preceded by a schools' half term break used by some for holidays abroad, particularly in continental Europe. It is also worth remembering that the volume of international travel is related to socio-economic status, and that variable was controlled for by the ONS analysis. Therefore, the second possibility represents a more useful, or at least additionally necessary, line of inquiry.

A relatively quick spread of coronavirus among Jews could happen due to the greater sociability of Jews. Jews with formal and informal links to the Jewish communal life attend communal events and celebrations-for example, bar/bat mitzvah parties, or festival activities such as those that occurred during the holiday of 
Purim in mid-March — and they pray regularly in groups (a minyan - a quorum of ten adults-is required for key parts of Jewish prayer). Previous research has shown that synagogue attendance in European Jewish communities (about 23\% attend at least weekly) is at a higher end of the European spectrum of weekly attendance of place of worship: 3-15\% of the total population in the United Kingdom, Scandinavian countries, Belgium, France, Spain, Germany, Austria and the Netherlands attend church weekly. The level of weekly synagogue attendance in the European Jewish communities resembles the levels of weekly church attendance in Italy (23\%) (Staetsky and Paltiel 2020, p. 29). Close contact in the context of communal activities, both ritual and social, could lead to greater prevalence of infection in the Jewish community. The hypothesis connecting social and religious involvement to greater exposure to coronavirus has been discussed in the context of the European societies (Albertini et al. 2020; Laliotis and Minos 2020; Oksanen et al. 2020). The arithmetical necessity of a greater prevalence of infection is more sick people, and the result of more sick people is more deaths-all other things (socio-economic situation, etc.) being equal. Jews do not need to be more vulnerable, in any biological sense, to the effects of the virus, for elevated mortality to occur; indeed, they can be less vulnerable in purely physically terms. It is just that due to close contact with other Jews in a variety of communal settings, the Jewish population may have become "overwhelmed" by the virus. Future scholarly conversation should focus closely on the sociability hypothesis, as it holds the greatest promise with respect to the epidemiological and demographic "detective story" of elevated Jewish mortality from coronavirus.

\section{Appendix 1}

\section{The illustration of compatibility: births}

Compatibility of the communal counts of Jewish births had been put to test in the past (Fig. 6), with good results, but the basic finding has been under-reported and under-appreciated. The number of children in single age groups in the 2011 Census was closely aligned with the communal counts of births (Fig. 6).

Some degree of incompatibility between the counts of births derived from the Jewish communal records (based on circumcisions) and the census-based numbers can be expected for ages above 1 due to the impact of migration at these ages. Census records are expected to contain children of migrants, while the counts of communal births cannot contain them, by definition. Thus, census counts of Jewish children aged above 1 are higher than what the numbers of births suggest for these age cohorts. The situation for those aged below 1 is different. There, the census count is lower than the number based on births. This apparent atypical mismatch of about 200 children below age 1 (the difference between 3853 and 3646 in 2010) closes after the adjustment for the undercounted strictly Orthodox Jewish children aged below 1 in 2011 (estimated number of 350). The phenomenon of undercount owes to the imperfection of the Census 2011 instrument and its unsuitability for 


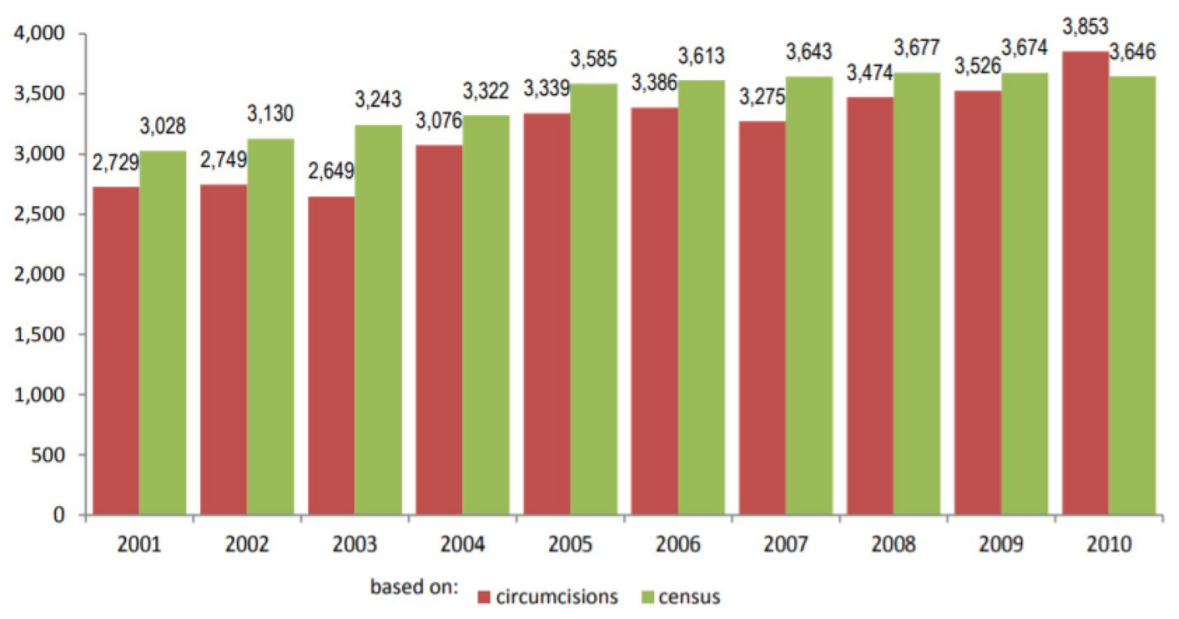

Fig. 6 Births in the Jewish community in the United Kingdom: estimates from the 2011 Census vs the Jewish communal statistics. Adopted from: Vulkan, D. 2013. Britain's Jewish community statistics 2012. The Board of Deputies of British Jews, p. 8

documenting the composition of large families (Staetsky and Boyd 2015, footnote 12, pp. 8-9; Staetsky and Boyd 2016, pp. 25-28).

With the new insight brought to us by the ONS record linkage exercise, we obtain the full picture of the interaction between the communal statistics and the Census. The most significant conclusion is that the national census and the Jewish communal statistics relate to the same "population body", in terms of size and characteristics. It follows that they can be reasonably used to populate the population equation of the form:

$$
P(t+1)=P(t)+B-D
$$

This was not obvious before.

As stated in the main body of this article, there are several implications to this conclusion for the British Jewish demographic statistics-all important. The latest finding produced by the ONS concerning deaths, coupled with the previous finding concerning births, significantly enhances the quality of our understanding of the basic demographic elements and calls for re-evaluation and/or dismissal of several uncertainties in British Jewish demography. In particular, these findings provide validation of the previously obtained conclusions in the field of research on Jewish mortality in the UK (Staetsky 2011b). In this paper, another major consequence is featured: better understanding of the heightened Jewish mortality from COVID-19.

\section{References}

Albertini, M., L. Sage and S. Scherer. 2020. Intergenerational contacts and Covid-19 spread: Omnipresent grannies or bowling together? Working Paper. Bologna: University of Bologna.

Aparicio, A. and S. Grossbard. 2020. Intergenerational residence patterns and COVID-19 fatalities in the EU and the US. IZA Discussion Papers No. 13452. Bonn: IZA-Institute of Labor Economics. 
Arpino, B., V. Bordone, and M. Pasqualini. 2020. No clear association emerges between intergenerational relationships and COVID-19 fatality rates from macro-level analysis. PNAS 17 (32): 19116-19121.

Balbo, N., I. Kashnitsky, A. Melegaro, F. Mesle, M. Mills, H. de Valk and D. de Vilhena. 2020a. Demography and the coronavirus pandemic. Population and Policy Brief 25. Berlin: Max Planck Society for the Advancement of Science on behalf of the collaborative network Population Europe.

Balbo, N., F. Billari and A. Melegaro. 2020b. The strength of family ties and COVID-19. Contexts, April 6, 2020. https://contexts.org/blog/structural-shocks-and-extreme-exposures/\#balbo. Accessed June 10, 2020.

Bilinski, A., and E. Emanuel. 2020. COVID-19 and excess all-cause mortality in the US and 18 comparison countries. Journal of the American Medical Association 324(20): 2100-2102.

Boyd, J., C. Lessof, and D. Graham. 2020. Acute disadvantage: Where are the needs greatest? JPR Paper. London: Institute for Jewish Policy Research. JPR_2020.Coronavrius_paper_1.3.Acute_disadvantage.October_2020.pdf

Branden, M., S. Aradhya, M. Kolk, J. Harkonen, S. Drefahl, B. Malmberg, M. Rostila, A. Cederstrom, G. Andersson, and E. Mussino. 2020. Residential context and COVID-19 mortality among adults aged 70 years and older in Stockholm: A population-based, observational study using individual-level data. Lancet Healthy Longevity 1: e80-88.

Brym, R., J. Neuman, and R. Lenton. 2019. 2018 survey of Jews in Canada. Environics Institute for Survey Research. Project Details (environicsinstitute.org).

Casale Mashiah, D. 2018. Vital statistics of the UK Jewish population: Births and deaths. JPR Report. London: Institute for Jewish Policy Research. https://www.jpr.org.uk/documents/JPR.2018.Vital_ statistics.Births_and_deaths.pdf

Casale Mashiah, D. and Boyd, J, 2017. Synagogue membership in the United Kingdom in 2016. JPR Report. London: Institute for Jewish Policy Research. download (jpr.org.uk)

Central Bureau of Statistics, Israel. 2019. Health and social profile of the localities in Israel 2011-2017. (Hebrew). https://www.cbs.gov.il/en/mediarelease/Pages/2019/Health-Social-Profile-Localities-inIsrael-2011-2017.aspx

Comas-Herrera, A., J. Zalakain, E. Lemmon, D. Henderson, C. Litwin, A. Hsu, A. Schmidt, G. Arling and J-L. Fernandes. 2020. Mortality associated with COVID-19 in care homes: International evidence. International Long Term Care Policy Network. 14 October 2020.

Davie Smith, G., N. Chatuverdi, S. Harding, J. Nazroo, and R. Williams. 2000. Ethnic inequalities in health: A review of UK epidemiological evidence. Critical Public Health 10(4): 375-408.

DellaPergola, S. 2020. World Jewish population, 2019, American Jewish Year Book 2019. Cham: Springer.

Dowd, J., L. Andriano, D. Brazel, V. Rotondi, P. Block, X. Ding, Y. Liu, and M. Mills. 2020. Demographic science aids in understanding the spread and fatality rates of COVID-19. PNAS 117(18): 9696-9698.

Dowd, J., P. Block, V. Rotondi, and M. Mills. 2020. Dangerous to claim 'no clear association' between intergenerational relationships and COVID-19. PNAS 117(42): 25975-25976.

Esteve, A., I. Permanyer, D. Boertien, and J. Vaupel. 2020. National age and coresidence patterns shape COVID-19 vulnerability. PNAS 117(28): 16118-16120.

Gaskell, K., M. Johnson, V. Gould, A. Hunt, N. Stone, W. Waites, B. Kasstan, T. Chantler, S. Lal, C. Roberts, D. Goldblatt, R. Eggo and M. Marks. 2021. Extremely high SARS-CoV-2 seroprevalence in a strictly-Orthodox Jewish community in the UK. Preprint from medRxiv, 03 Feb 2021. https://doi. org/10.1101/2021.02.01.21250839, PPR: PPR277515

Graham, D. 2013a. Thinning and thickening: Geographical change in the UK's Jewish population, 20112011. JPR Paper. London: Institute for Jewish Policy Research. Institute for Jewish Policy Research: Our publications (jpr.org.uk)

Graham, D. 2013b. 2011 Census results (England and Wales): A tale of two Jewish populations. JPR Paper. London: Institute for Jewish Policy Research. 2011 Census results - A Tale of Two Jewish Populations.pdf (jpr.org.uk)

Graham, D. 2013c. 2011 Census results (England and Wales): Initial insights into Jewish neighbourhoods. JPR Paper. London: Institute for Jewish Policy Research. 2011 Census results - Initial insights into Jewish neighbourhoods.pdf (jpr.org.uk)

Graham, D. and Caputo, M.L. 2015. Jewish families and Jewish households: Census insights about how we live. JPR Report. London: Institute for Jewish Policy Research. JPR_Census_Jewish_families_ and_Jewish_households_report_March_2015.pdf 
Harding, S. 1998. The incidence of cancers among second-generation Irish living in England and Wales. British Journal of Cancer 78(7): 958-961.

Harding, S. 2000. Examining the contribution of social class to high cardiovascular mortality among Indian, Pakistani and Bangladeshi male migrants living in England and Wales. Health Statistics Quarterly 5: 26-29.

Harding, S. 2003. Mortality of migrants from the Indian subcontinent to England and Wales: Effect of duration of residence. Epidemiology 14(3): 287-292.

Harding, S. 2004. Mortality of migrants from the Caribbean to England and Wales: Effect of duration of residence. International Journal of Epidemiology 33 (2): 382-386.

Harding, S., and R. Balarajan. 1996. Pattern of mortality in second generation Irish living in England and Wales: Longitudinal study. British Medical Journal 312: 1389-1392.

Ikram, U., J. Mackenbach, S. Harding, G. Rey, R. Bhopal, E. Regidor, M. Rosato, K. Juel, K. Stronks, and A. Kunst. 2016. All-cause and cause-specific mortality of different migrant populations in Europe. European Journal of Epidemiology 31: 655-665.

Laliotis, I. and D. Minos, D. 2020. Spreading the Disease: The Role of Culture (20/12). Discussion Paper Series. London, UK: Department of Economics, City, University of London.

Lee, R., and J. Goldstein. 2020. Demographic perspectives on the mortality of COVID-19 and other epidemics. PNAS 117(36): 22035-22041.

Marmot, M., A. Adelstein, and L. Bulusu. 1984. Lessons from the study of immigrant mortality. Lancet 323: 1455-1457.

OECD. 2020. Excess mortality: Measuring the direct and the indirect impact of COVID-19. Tackling coronavirus (COVID19): Contributing to a global effort. OECD Report.

ONS. 2015. How religion has changed in England and Wales. How religion has changed in England and Wales - Office for National Statistics (ons.gov.uk)

ONS. 2020a. Coronavirus (COVID-19) related deaths by religious group, England and Wales, 2 March to 15 May 2020. https://www.ons.gov.uk/peoplepopulationandcommunity/birthsdeat hsandmarriages/deaths/articles/coronaviruscovid19relateddeathsbyreligiousgroupenglandandwal es/2marchto 15 may 2020

ONS. 2020b. Coronavirus (COVID-19) related deaths by ethnic group, England and Wales, 2 March to 10 April 2020. https://www.ons.gov.uk/peoplepopulationandcommunity/birthsdeathsandmarri ages/deaths/articles/coronavirusrelateddeathsbyethnicgroupenglandandwales/2march2020to10a pril2020

ONS. 2020c. Coronavirus (COVID-19) related deaths by ethnic group, religious group and disability, England and Wales Methodology. Technical appendix for the coronavirus-related deaths by ethnic group, religious group and disability (England and Wales) articles. https://cy.ons.gov.uk/ peoplepopulationandcommunity/birthsdeathsandmarriages/deaths/methodologies/coronaviru scovid19relateddeathsbyethnicgroupreligiousgroupanddisabilityenglandandwalesmethodology

Oksanen, A., M. Kaakinen, R. Latikka, L. Savolainen, L. Savela, and A. Koivula. 2020. Regulation and trust: 3-month follow-up study on COVID-19 mortality in 25 European countries. JMIR Public Health \& Surveillance 6(2): e19218.

Pew Research Center. 2013. A portrait of Jewish Americans: Findings from a Pew Research Center Survey of U.S. Jews. jewish-american-full-report-for-web (3).pdf

Rees, P., P. Wohland, and P. Norman. 2009. The estimation of mortality for ethnic groups at local scale in the United Kingdom. Social Science and Medicine 69(11): 1592-1607.

Scott, A., and I. Timaeus. 2013. Mortality differentials 1991-2005 by self-reported ethnicity: Findings from the ONS Longitudinal Study. Journal of Epidemiology and Community Health 67: $743-750$.

Staetsky, L. 2011. The role of smoking in the explanation of the Israeli Jewish pattern of sex differentials in mortality. Population Studies 65 (2): 231-244.

Staetsky, L. 2011. Mortality of British Jews at the turn of the 20th century in a comparative perspective. European Journal of Population 27(3): 361-385.

Staetsky, L. Daniel., and A. Hinde. 2009. Unusually small sex differentials in mortality of Israeli Jews: What does the structure of causes of deaths tells us? Demographic Research 20(11): 209-252.

Staetsky, L. Daniel., and A. Hinde. 2015. Jewish mortality reconsidered. Journal of Biosocial Science 47(3): 376-401.

Staetsky, L. Daniel and Boyd, J. 2015. Strictly Orthodox rising: What the demography of British Jews tells us about the future of the community. JPR Report. London: Institute for Jewish Policy Research. https://archive.jpr.org.uk/download?id=2514 
Staetsky, L. Daniel and Boyd, J. 2016. The rise and rise of Jewish schools in the United Kingdom: Numbers, trends and policy issues. London: Institute for Jewish Policy Research. download (jpr.org.uk)

Staetsky, L. Daniel and DellaPergola, S. 2020. Jews in Austria: A demographic and social portrait. European Jewish Demography Unit/JPR Report. London: Institute for Jewish Policy Research. download (jpr.org.uk)

Staetsky, L. Daniel and A. Paltiel. 2020. COVID-19 mortality and Jews: A global overview of the first wave of the coronavirus pandemic, March to May 2020. European Jewish Demography Unit/JPR Report. London: Institute for Jewish Policy Research. Institute for Jewish Policy Research: Our publications (jpr.org.uk)

The Economist. 2020. Tracking covid-19 excess deaths across countries. https://www.economist.com/ graphic-detail/2020/07/15/tracking-covid-19-excess-deaths-across-countries.

The Financial Times. 2020. Coronavirus tracked: The latest figures as countries fight covid-19 resurgence, https://www.ft.com/content/a2901ce8-5eb7-4633-b89c-cbdf5b386938.

Wild, S., C. Fischbacher, A. Brock, C. Griffiths, and R. Bhopal. 2007. Mortality from all causes and circulatory disease by country of birth in England and Wales 2001-2003. Journal of Public Health 29(2): 191-198.

Wild, S., and P. McKeigue. 1997. Cross sectional analysis of mortality by country of birth in England and Wales, 1970-92. BMJ: British Medical Journal 314(7082): 705-710.

Wohland, P., P. Rees, J. Nazroo, and C. Jagger. 2015. Inequalities in healthy life expectancy between ethnic groups in England and Wales in 2001. Ethnicity and Health 20(4): 341-353.

Publisher's Note Springer Nature remains neutral with regard to jurisdictional claims in published maps and institutional affiliations.

L. Daniel Staetsky is a Senior Research Fellow at JPR and Director of its European Jewish Demography Unit. His expertise spans the disciplines of demography, applied statistics and economics, and he is a former researcher and analyst at the Central Bureau of Statistics in Israel and at RAND Europe. He holds an MA in demography from the Hebrew University of Jerusalem and a PhD in social statistics from the University of Southampton. He specialises in Jewish, European, Israeli and Middle Eastern demography. His work in demography has been widely published, and he focuses particularly on the major puzzles of contemporary demography, such as relatively high Jewish longevity, divergence of longevity paths between different Western countries and stagnating fertility in the context of the developing world. He has authored and co-authored about forty manuscripts covering the topics of demography, survey methodology, social statistics and the quantitative study of antisemitism. 